\title{
Prospective Teachers' Understanding of the Constant $\pi$ andtheir Knowledge of How to Prove its Constant Nature through the Concept of Linearity ${ }^{1,2}$
}

\author{
LEUNG, K. C. Issic \\ Department of Mathematics and Information Technology, Hong Kong Institute of Education, \\ Hong Kong SAR,China; Email: ikcleung@ied.edu.hk
}

(Received November 3, 2013; Revised November 11, 2013; Accepted March16,2014)

\begin{abstract}
When taught the precise definition of $\pi$, students may be simply asked to memorize its approximate value without developing a rigorous understanding of the underlying reason of why it is a constant. Measuring the circumferences and diameters of various circles and calculating their ratios might just represent an attempt to verify that $\pi$ has an approximate value of 3.14, and will not necessarily result in an adequate understanding about the constant nor formally proves that it is a constant. In this study, we aim to investigate prospective teachers' conceptual understanding of $\pi$, and as a constant and whether they can provide a proof of its constant property. The findings show that prospective teachers lack a holistic understanding of the constant nature of $\pi$, and reveal how they teach students about this property in an inappropriate approach through a proving activity. We conclude our findings with a suggestion on how to improve the situation.
\end{abstract}

Keywords: teachers' professional knowledge, proofs and proving tasks, mathematical constants, linearity

MESC Classification: F40

MSC2010Classification: $97 \mathrm{~F} 40$

\section{INTRODUCTION}

When learning the concept of mathematical variables in secondary algebra courses, students inevitably come across corresponding terms that are introduced simultaneously mathematical constants.Many students may be told in their lessons that a constant is simply a

\footnotetext{
${ }^{1}$ This study was supported by the Internal Research Grant (RG57/09-10) ofthe Hong Kong Institute of Education.

2 A draft version of the article was presented at the 2013JointInternational Conference onMathematics Education held at SeoulNational University, Seoul151-742, Korea; November 1-2, 2013(cf.Leung, 2013).
} 
fixed number that cannot be changed. To young minds, the idea that a certain number is fixed and should not, and cannot be changed is not a difficult one to grasp. It is not until they learn about representation of a variable number by a letter such as $\mathrm{x}$ that they may begin to feel that some fixed, invariant quantity is represented by a corresponding numeral called a constant. Yet constants are not emphasized in curricula in which learning the properties of constants is not an explicit part of the syllabus(CDC, 1999; CDC \& HKEAA, 2007).

The concept of mathematical constants is an important foundation for students' further learning of many related concepts in physical sciences, such as acceleration due to gravity. Learning the concept of constants refers to developing an understanding of the underlying meaning of fixed numbers, such as their originality, how their magnitudesare evaluated, and their applications. Learning the underlying meaning of constants should include the role they play in different mathematical contexts, such as that they can represent the coefficients of a variable, the parameters of an equation, a ratio of two specific quantities (e.g. the famous Archimedean constant $\pi$ ), a scalar multiplier of a vector, the limit of a convergent series, or an exponential decay factor. It would be very appealing to students to realize that understanding the concept of mathematical constants is far more significant than simply treating them as fixed numbers.

Teaching the concept of mathematical constants does not merely involve introducing fixed numbers to students; such constants have a specific role in explaining their original creation. Telling students about the motivation for creating such constants in a mathematical context is thus a necessary and indispensable aspect of mathematics lessons. Taking $\pi$ as an example, developing a holistic understanding of its definition, numerical representation and properties, the role it plays in various mathematical contexts, and techniques for applying it in different real-life situations should be common goals of mathematics teachers and learners.

From the time we first encounter physical constants in high school science lessons, we are told that many constants exist and that each such constant has a fixed value represented by a certain magnitude. The quick and easy association made in this context is that the meaning of a constant is a fixed value that is universally invariant in a theoretical sense. It takes great effort for teachers to explain why scientists are motivated to create such constants. The question "Why bother to learn about these fixed numbers?"is the common refrain of students. The conclusion commonly reached is that the invariant nature of constants is extremely useful, as they enable us to predict other quantities through the relations between constant and other variables. For example, the acceleration due to gravity, as a universal constant, is used to predict the escape velocity of a rocket launched on the Earth's surface.On an elementary level, the constant $\pi$ is used to predict or evaluate the distance traveled by a vehicle when the diameter of its wheels and the number of times its wheels turn are known. Many students take for granted the concept that the value $\pi$ remains unchanged for different wheel sizes. In a more mathematical sense, teachers may be asked why $\pi$ is a constant when they introduce $\pi$ to their 
students. Does the value of $\pi$ increase if the circle becomes larger? In solving related problems, we simply assume that $\pi$ is a constant, and proceed to find the required answer by calculating formulae in which $\pi$ is assigned the approximate value of 3.14. This is because we are all told that $\pi$ is a constant and, for every circle, the value of $\pi$ will be unchanged. The problem here is how to explain to students that $\pi$ is a constant. Even though we introduce historic literature on how $\pi$ is evaluated and estimated, what is lacking is a complete argument that leads to the conclusion that it is constant by its nature. In short, it is difficult to convince students that $\pi$ is a constant.

The Hong Kong primary school curriculum (CDC 1999; CDC \& HKEAA, 2007) does not include any proof of the constant nature of $\pi$; in secondary school, the curriculum simply accepts its status as a constant without providing a rigorous understanding of why this is so. Regardless of whether this reflects an attitude problem among teachers who are unwilling to investigate the constant nature of $\pi$, or whether teachers simply gloss over the importance of understanding $\pi$ by adopting a less rigorous attitude, both attitudes will have a negative effect on classroom teaching quality. Moreover, the ability of students to rigorously pursue mathematical excellence is likely to be hindered. Based on these observations, it seems that we should develop prospective teachers' knowledge of how to prove that $\pi$ is a constant in a logical and systematic manner.

\section{THEORETICAL FRAMEWORK}

In-depth studies carried out in recent decades show how well-prepared prospective teachers understand certain topic-specific mathematical concepts, such as the definitions of functions and composite functions (Meel, 1999; Sanchez \&Llineares, 2003), the underlying meaning of division of fractions (Li \&Kulm, 2008; Li \& Huang, 2008; Ball 2005), their ability to justify examples and counter-examples in teaching the concepts of limits and continuity in calculus (Gruenwald\&Klymchuk, 2003) and pre-service teachers' knowledge of proof by mathematical induction (Styliandies, Styliandies\&Philippou, 2007). Most, if not all, of these studies show those prospective teachers generally lack a complete understanding of the underlying meaning of such topic-specific concepts and have difficulty teaching them. They simply do not possess the knowledge expected of professional teachers, who must know what they teach. Wu (2011) described the knowledge teachers should possess in precise terms by saying:

...only that they must know the content of what they teach to their students.Here I am using the word - knowin the unambiguous sense that mathematicians understand this term: knowing a concept means knowing its precise definition, its intuitive content, why it is needed, and in what contexts it plays a role, and knowing a technique means knowing its precise statement, when it is appropriate to apply it, how to prove 
that it is correct, the motivation for its creation, and, of course, the ability to use it correctly in diverse situations (p. 380).

In the context of the constant $\pi$, in addition to being able to describe its definition, estimate its value and know how to apply it, we must also know how to demonstrate, or in a stricter sense, prove, its constant nature. The question that subsequently arises is: what is meant by the term "proof"? Balacheff (1991, p. 109) refers to proof as a discourse whose aim is to establish the truth of a conjecture. However, he emphasizes that it is not necessarily a mathematical proof. For mathematical proof (of a proposition), according to Balacheff (1991), we generally refer to a series of deductive reasons for sequentially axiomatic arguments based on true assumptions of known results and fundamental postulates. In his paper, Griffiths (2000, p. 2) precisely defines mathematical proof as a formal and logical line of reasoning that begins with a set of axioms and moves through logical steps to a conclusion. Balacheff (2010) further explains how to bridge knowing and proving in mathematics. His argument pinpoints the fact that teachers may not be able to formulate a formal proof of the constant nature of $\pi$, for example, even though they are secure in the knowledge it is a fact. He adds that it is not feasible to learn mathematics without learning mathematical proofs, writing as follows:

Hence, the answer to the question: "Can one learn mathematics without learning what a mathematical proof is and how to build one?" is "No." (p. 115)

As mathematics teachers, we may have the experience of students asking why the famous number $\pi$ is a constant. The reactive answer could be to tell students to construct many circles to verify the consistency of the ratio of their circumferences to their diameters. Though contemporary mathematics educators have not always agreed on what does and does not constitute a proof (Dreyfus 1999), this is still not a proper or formal proof, as continuous measurements can serve only as a kind of verification, and are not sufficiently rigorous to be called a proof. According to Blum \& Kirsch (1991), in our case, verifying the constant nature of $\pi$ by obtaining values from several circles of different sizes can provide proof only at the first of its three primary levels: experimental proof, intuitional proof and formal (scientific) proof. To a great extent, experimental proof (measurement of various circles) is only a kind of verification. We may wonder how to prove that $\pi$ is a constant, or at least demonstrate a mathematically, logically acceptable sequence of arguments to deduce that this is so. Teachers may simply tell their students to accept that it is a constant in the sense that its value is consistent for every single circle. However, giving formal proof of the constant nature of $\pi$ will certainly lead to better training to develop students' understanding of rigour in mathematical proofs, which we believe is beneficial to further learning of advanced mathematics. Although Balacheff (2010) asserts that "learning and understanding mathematics cannot be separated from understanding its intrinsic means for validation: mathematical proofs". Another study by Weber (2001) shows that undergraduate students may not even be able to demonstrate tech- 
niques for proving mathematical propositions.

According to Ball, Lubienski\&Mewborn (2001), even university students majoring in mathematics may not have sufficient subject content knowledge to enable them to teach the discipline. As a particular example, Li \& Huang (2008) verified that there is a discrepancy between what many pre-service teachers perceive to be their level of knowledge about fractional division and their actual knowledge about it. In another investigation, Ball (2005) shows how much of an effect teachers' knowledge has on student achievement. In the MT21 Report, Schmidt et al. (2007) put the priority in teachers' preparation (before beginning their teaching career) on improvements aimed at filling the gap in teacher education between Western nations and their Eastern counterparts. It seems that teachers must have a sound understanding of the concepts they teach before their students can understand them.

In his most widely cited study, Shulman (1986) identifies two components of knowledge about mathematics teaching: mathematical content knowledge (MCK) and pedagogical content knowledge (PCK). Hill, Ball \& Schilling (2008) further generalised these two components into subject matter knowledge (SMK) and PCK, in which the former consists of common content knowledge, specialised content knowledge and knowledge at the mathematical horizon, whereas PCK consists of knowledge of the curriculum, knowledge of teaching and knowledge of students, etc. A well-equipped teacher should theoretically possess these two components of knowledge.

In contrast, Blomhøj\& Valero (2007) suggest that changes to prospective teacher education are more likely to bring improvements in classroom instruction, especially if "teachers' mathematical knowledge gets closely related to didactical knowledge in contexts of teaching experience or concrete teaching situations". During the educational reform period, higher order thinking skills — such as reasoning, proofs and argumentation—have drawn much attention among the mathematics education community (Wong, Han \& Lee, 2004). In their investigation, Schwarz et al. (2008) compare the competencies of prospective mathematics teachers from three distinct regions: Hong Kong, Australia and Germany. It is found that prospective teachers from these regions cannot adequately execute mathematics proofs even at the lower secondary level. It appears that prospective teachers do not possess sufficient skills and knowledge to enable them to teach proofs, even though they may satisfy mandatory mathematical background requirements. Our investigation of teachers' knowledge about the proof of $\pi$ and related proving activities supports our firm belief that teachers' knowledge of teaching is a matter of concern in facilitating effective student learning about conceptual understanding of the constant nature of $\pi$. This knowledge will make a partial contribution to teachers' PCK and SMK.

In their investigation, Stylianides\& Ball (2008) identify two main components constituting knowledge about proof for engaging students in proving: 
(1) Knowledge about the logico-linguistic structure of proof; and

(2) Knowledge of the situation for proving.

The former generally refers to knowledge of arguments, explanations and logical derivation of proofs.The latter is further subdivided into two components (p. 313):

- Knowledge of different kinds of proving tasks (KPT); and

- Knowledge of the relationship between proving tasks and proving activity (KRTA).

They further argue that it is important for teachers to possess knowledge of different kinds of proving tasks (KPT) to enable them to draw analogies to the domain of proof in teaching, and to have knowledge of the relationship between proving tasks and proving activity (KRTA), that is, to understand the critical mathematical aspect of the proving activity that can be provoked by certain kinds of tasks (Stylianides\& Ball, 2008). This understanding is essential in teaching proofs in a mathematics lesson. Hence, a study of how rich prospective teachers' knowledge is about the constant nature of $\pi$, conducted from the KPT and KRTA perspectives, would be of great interest and provide practical implications for the improvement of mathematics teacher knowledge competency.

Based on our assumptions stated above, we investigated, through proper instrumental item questions on teaching proofs and executing proving activities about the constant nature of $\pi$, how well-equipped our prospective teachers are in terms of the two key components of knowledge of situation for proving.

(a) To assess their knowledge of different kinds of proving tasks (KPT), prospective teachers were tested on their:

- Knowledge of using the concept of linearity to prove the constant nature of $\pi$. This linear relationship between the circumference and diameter of a given circle is shown as straight line plotted from the points representing the ordered pairs of the respective circumferences (C) and diameters (D) (see Figure 1); and

- Ability to connect the geometric property to algebraic derivation in proving the constant nature of $\pi$ geometrically.

(b) To assess their knowledge of the relationship between proving tasks and proving activity (KRTA), prospective teachers were tested on their.

- Ability to describe the advantages and disadvantages of various methods of proving the constant nature of $\pi$;

- Responses to students' enquiries about its definition and constant property;

- Approaches used to handle discrepancies generated through experimental activities; and

- Competency to choose a suitable approach to teach the concept of mathematical constants, $\pi$ in our case. 
We must emphasize that the full extent of prospective teachers' knowledge about proof for engaging students in proving may not be demonstrated in full by the limited coverage of our instruments. We hope that the investigation will serve as a catalyst for further examination of prospective teachers' competence in the area of proofs and proving. We do not specifically measure prospective teachers' knowledge about the logico-linguistic structure of proof; as such knowledge is reflected by their subject matter knowledge, in terms of their logical deductive and inductive reasoning skills and mathematical language proficiency.

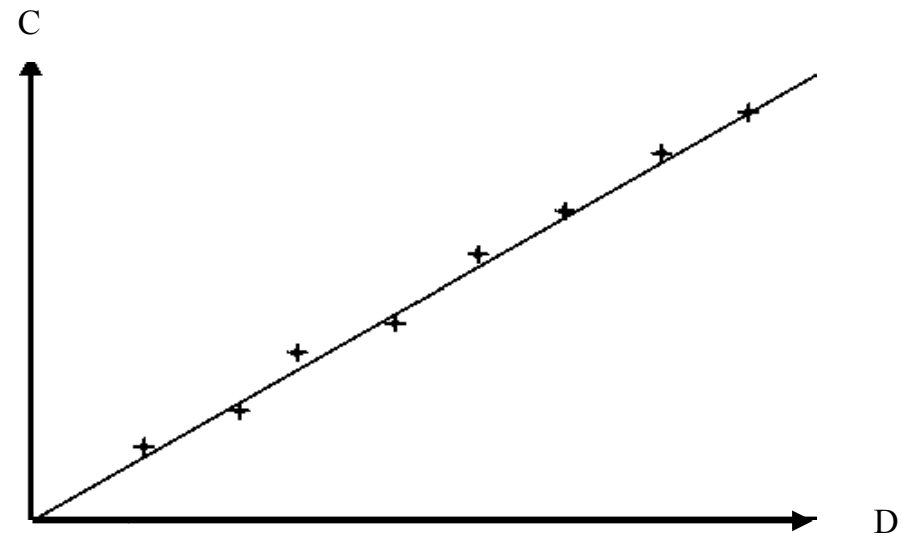

Figure 1.The best-fitting straight line connecting points representing the circumference (C) and diameter (D) ofvarious circles

We selected a few classes of prospective teachers from four colleges of education in Hong Kong. These students were studying for a Bachelor in Education (BEd) or Postgraduate Diploma of Education (PGDE), majoring in mathematics. In general, they had studied high school (upper secondary) mathematics courses before beginning their tertiary studies. In their BEd or PGDE studies, some college-level mathematics courses are also core subjects in their programs, such as calculus, linear algebra, Euclidean geometry, introductory statistics and statistical modeling, and real analysis. After graduating, the participants would be qualified to teach mathematics in any local secondary school. After two regular years of full-time teaching, they would be entitled to register for a professional license enabling them to pursue their teaching career. The participants were all Year 3 and Year 4 students studying towards a BEd. We collected 76 completed questionnaires from the participants, using seven instrumentalitems (see Appendices I \& II) to investigate prospective teachers' knowledge of how to prove the constant nature of $\pi$.

The questionnaire items included three hypothetical situations, each of which demonstrated a particular teaching activity implemented by one of the three students involved. In this activity, the students attempted to verify the constant nature of $\pi$. The item questions required the prospective teachers to comment on each of the methods, identifying their advantages and 
disadvantages, and to respond to students' queries on the conceptual understanding of how the value of $\pi$ is found experimentally (see Appendix I). The participants were then asked to provide an alternative proof for the constant nature of $\pi$ in addition to those used by students in the activities hypothetically described in the questionnaire. The best and most easily understood method of proof is to use the property of similarity of circles. The connection between algebraic and geometric concepts was the key ingredient of subject knowledge tested among the participants.

The three hypothetical methods stated in the questionnaire that the three students used to find the value of $\pi$ are basically experimental by nature. Students first drew several circles, then calculated the ratio of the circumference and the diameter after measuring them in each circle. The students thus found the ratio and then the estimated value of $\pi$ after performing some simple division calculations. However, discrepancies arose in:

- Calculating $\pi$ by dividing the circumference by the diameter;

- Calculating $\pi$ by dividing the diameter by the circumference; and

- Finding $\pi$ by estimating the slope of a straight line plotted on a graph compiled from the ordered pairs of circumferences and diameters measured.

Some of our item questions were aimed at testing how to resolve these discrepancies generated by the students' experiments from various perspectives. In light of how Wu (2011) defines knowing a mathematical concept, and in particular how to prove that it is correct, we aimed to use a proving activity to test prospective teachers' knowledge of proofs and proving tasks concerning the invariant nature of the magnitude of $\pi$.

We must be precise in explaining that when we used the term "finding the value of $\pi$ " in the hypothetical situations described in the questionnaire, we did not specify whether there was only one fixed value of $\pi$ or many possible values for $\pi$. Students sought to find an approximate value, yet,they did not know whether it was aconstant.

\section{DATA ANALYSISAND RESULT}

Because we are investigating prospective teachers' knowledge competency, our target population is prospective teachers in undergraduate years three and year four, or PGDE from four local universities. Our sample size (76 questionnaires data sets collected) is relatively small. We analyze their responses to the item questions from a qualitative perspective only according to three main reasons and interpretational perspectives: mathematical, didactical and practical. This means that when valid responses are expressed in terms of a mathematical judgment or reasoning on proofs and proving activities, we put them in the mathematical category; when responses are expressed as taking account of pedagogical reasons such as students' capabilities, task design, smoothness of lesson plan execution, etc., we place them 
in the didactical category; and when students are told to "measure more circles" or "be more careful in using measuring tools", etc., we place the teacher's response in the practicalcategory. To be clear, valid responses refer to answers in which the correctness or appropriateness of the method used can be judged regardless of the category. For example, one prospective teacher's response in saying "use a better calculator" to answer a question on how to reduce discrepancies in finding the value of $\pi$ was valid, because we can judge whether or not using a better calculator is appropriate. In contrast, invalid responses, as well as irrelevant, wrong, or meaningless responses or answers, are categorized as irrelevant or others. The coding rules are applied by two independent mathematics educators. Discrepancies in their categorization of responses are regulated by repeat codes assigned by a third educator.

\section{Reasons for discrepancies in measuring the value of $\pi$ and methods to reduce them}

When answering a question about why the three students found three different values and how to reduce the differences between them, prospective teachers overwhelmingly took the view (93.4\%) that it was because of the experimental setup, instrument errors and human error in measurement - the first principle (1st principle) of conducting scientific experiments. Typical responses relating to the first principle of scientific experimentation also included suggesting more trials (measuring more circles) or using better instruments $(85.5 \%)$ to improve accuracy and reduce discrepancies. The participants did not seem to consider other more didactical reasons, such as classroom management, a lack of interest among students or impartial attempts. They seemed to assume students were very eager to complete the task the teacher assigned, a highly unrealistic scenario in a real classroom setting. Many students find direct measurement activities monotonous. No prospective teachers thought the discrepancies observed were caused by students' mathematics knowledge, and only one prospective teacher suggested reducing the magnitude of discrepancies by considering them from a mathematical perspective, saying "review the definition of errors..."(Script 048). This teacher did not quite seem to understand that knowing how to define errors will not necessarily lead to accuracy. The irrelevant/others category in Table 1 refers to responses such as "I do not know"(Script 023) or asking to "provide data to students directly"(Script 060).

Table 1. Reasons for discrepancies in measuring the value of $\pi$ and different methods used to reduce discrepancies in its estimated value

\begin{tabular}{ccccccc}
\hline & $\begin{array}{c}\text { Mathe- } \\
\text { matical }\end{array}$ & $\begin{array}{c}\text { Practical } \\
(1 \text { stprinciple })\end{array}$ & $\begin{array}{c}\text { Didactical } \\
\text { Irrelevance }\end{array}$ & Others & Blank & Total \\
\hline $\begin{array}{c}\text { Causes of discrepan- } \\
\text { cies }\end{array}$ & 0 & 71 & 2 & 3 & 0 & 76 \\
\hline $\begin{array}{c}\text { Methods used to } \\
\text { reduce }\end{array}$ & 1 & $93.4 \%$ & $2.6 \%$ & $4.0 \%$ & $0.0 \%$ & \\
\hline . & $1.3 \%$ & $85.5 \%$ & $2.6 \%$ & $4.0 \%$ & $6.6 \%$ & 76 \\
\hline
\end{tabular}




\section{Advantages and disadvantages of various methods}

In a similar manner to that described in the previous section, we distinguish between prospective teachers' responses with explanations to being asked about the advantages and disadvantages of the three respective methods into four categories: mathematical, didactical, practical and irrelevant. More specifically, mathematical refers to responses in which prospective teachers considered students' subject knowledge only. Didactical refers to responses whereby prospective teachers considered the suitability of the experiment (activity) being implemented according the lesson design: whether it was explorative, how students might discover the expected result, the suitability of using a guided or unguided discovery approach, etc. Practical considerations refer to the efficiency of measurement tools (e.g. rulers,strings, etc.) used and how skillfully students used them. The remaining responses, such as those referring to reasons relating to the environment or classroom conditions, are placed in the irrelevant category. For example, 10 counts in Mathematical-Adv in Table 2 refers to those responses telling the advantages of employing Method A in the Mathematical perspective.

Table 2.Prospective teachers' knowledge about the advantages and disadvantages of the three experiments used by the three respective students

\begin{tabular}{ccccccccccc}
\hline & \multicolumn{2}{c}{ Mathematical } & \multicolumn{2}{c}{ Didactical } & \multicolumn{2}{c}{ Practical } & \multicolumn{2}{c}{ Irrelevant/ others } & \multicolumn{2}{c}{ Blank } \\
\cline { 2 - 12 } & Adv & Disadv & Adv & Disadv & Adv & Disadv & Adv & Disadv & Adv & Disadv \\
\hline $\begin{array}{c}\text { Original } \\
\text { definition }\end{array}$ & 10 & 5 & 7 & 8 & 44 & 38 & 10 & 5 & 5 & 20 \\
(Method A) & $13.2 \%$ & $6.6 \%$ & $9.2 \%$ & $10.5 \%$ & $57.9 \%$ & $50 \%$ & $13.2 \%$ & $6.6 \%$ & $6.6 \%$ & $26.3 \%$ \\
\hline Reciprocal & 11 & 6 & 4 & 9 & 30 & 44 & 6 & 6 & 25 & 11 \\
(Method B) & $14.5 \%$ & $7.9 \%$ & $5.3 \%$ & $11.8 \%$ & $39.5 \%$ & $57.9 \%$ & $7.9 \%$ & $7.9 \%$ & $32.9 \%$ & $11.8 \%$ \\
\hline Linearity & 33 & 18 & 5 & 9 & 19 & 27 & 8 & 8 & 11 & 14 \\
$($ Method C) & $43.4 \%$ & $18.4 \%$ & $6.6 \%$ & $11.8 \%$ & $25 \%$ & $35.5 \%$ & $10.5 \%$ & $10.5 \%$ & $11.8 \%$ & $18.4 \%$ \\
\hline
\end{tabular}

The frequency counts show that more prospective teachers paid attention to accuracy in measuring the value of $\pi$ than did those who paid attention to mathematical and didactical reasons. These responses concerning the advantages and disadvantages of each method are skewed toward the practical category $(57.9 \%$ and $50.0 \%$ for the advantages and disadvantages of Method A, respectively; $39.5 \%$ and $57.9 \%$ for the advantages and disadvantages of Method $\mathrm{B}$, respectively; see Table 2). Prospective teachers seemed to believe that the concept of a constant $\pi$ would be taught effectively if students were more careful and skillful in their measurement procedures. Even though direct measurement (an experimental approach) is a more or less informal method of proving the concept and constant property of $\pi$, we expected prospective teachers to be able to identify its advantages and disadvantages by considering 
mathematical and didactical reasons. However, the statistics show that many of them tend to consider both its advantages and disadvantages from a practical perspective. The hidden assumption prospective teachers may make is that $\pi$ has to be a constant to give a mathematical sense to its accuracy. An experimental activity of this kind will be executed in a common sequential order:

\section{Measurement - Finding - Verification - Conclusion}

Prospective teachers considered accuracy in finding the value of $\pi$ important. At least this reflects their belief that the more accurate the values students obtain, the more easily the teacher can explain the constant property of $\pi$. The above procedural steps seem to represent a legitimate approach preferred by prospective teachers in demonstrating its proof.

A large number of responses also argued for the mathematical advantages of employing Methods $\mathrm{C}$ in comparison with Method A and $\mathrm{B}$. This may reflect a belief among prospective teachers that different approaches may stimulate students' mathematical thinking in the course of the experiment; however, other prospective teachers seem to think it risky (disadvantageous) to use these two methods. In other words, they may think that although Method A is quite safe from a mathematical perspective, it is difficult for students to use the other two less common methods, even though they might acquire more mathematical knowledge by doing so.

In a consistent finding, relatively few prospective teachers considered the advantages and disadvantages of the three methods from a didactical perspective, as they tended to treat the experiment as a routine activity involving measuring something accurately. The level of preliminary mathematics knowledge required to carry out the experiments efficiently was relatively low. Didactical judgment of the adequacy of the three methods thus plays a more important role. To a certain extent, the low percentage of responses made from the didactical perspective reflects a KRTA weakness among prospective teachers, particularly where the three methods represent attempts to find the approximate value of $\pi$ and verify its constant property.

In addition, the large number of practical responses prospective teachers made in relation to student B's method shows they consistently expected the student to consider running more trials in the hope of obtaining a more accurate measurement of $\pi$. Again, these responses show both KPT and KRTA weaknesses among prospective teachers. More measurements do not guarantee reduced measurement error, while taking many trial measures is not a scientifically realistic approach. The opposite effect may occur if students find that measuring more circles generates more errors. This will affect students' belief in the constant nature of $\pi$.

According to Dreyfus (1999, p. 105), teachers should be able to relate experimentally based reasoning which is derived from the measurement of data in our case to whether it can be justified as a prerequisite for an explanation and as an argument for a conjecture. This justification will eventually provide a clue on how to prove a particular proposition. The 
responses made to this question show that prospective teachers still have some degree of weakness in their knowledge of this issue.

\section{Alternative definition of $\pi$-what is wrong with the reciprocal?}

Regardless of the historical reasons (e.g. finding the value of $\pi$ by continuously cutting a circle), using the ratio of the circumference of a circle to its diameter is simply a convention employed to represent $\pi$. Using the reciprocal of the ratio to define $\pi$ is not mathematically inconsistent with the intention of its original definition. Of the prospective teachers examined here, $38.2 \%$ (29 out of 76 responses in the irrelevant category; see Table 3) still sought to convince their students that we have used such a measure of $\pi$ for a long time, saying it is a convention we should simply follow. Prospective teachers were not able to demonstrate that the reciprocal of a constant is also a constant; 44.7\% (34 out of 76) tried to convince their students from a practical perspective. Some even responded by saying that it will be more convenient to use a $\pi$ larger than 1" because the reciprocal will be less than unity. Prospective teachers' responses from a practical perspective were quite consistent, even though defining $\pi$ as larger than 1 does not violate mathematical reasoning. As a proving activity for lessons, investigating the reciprocal of $\pi$ is still a good experience for students. However, prospective teachers do not seem to accept such an irregular approach.

Table 3.Consideration of taking an alternative value of $\pi$ - reciprocal of the value in the original definition

\begin{tabular}{ccccccc}
\hline \multirow{3}{*}{ Counts } & Mathematical & Didactical & Practical & $\begin{array}{c}\text { Irrelevant/ } \\
\text { others }\end{array}$ & Blank & Total \\
\cline { 2 - 6 } & 7 & 1 & 34 & 29 & 5 & 76 \\
& $9.2 \%$ & $1.3 \%$ & $44.7 \%$ & $38.2 \%$ & $6.6 \%$ & \\
\hline
\end{tabular}

\section{$\pi$ is independent of the size of a circle}

When challenged by students on the reason $\pi$ remains unchanged as the size of the circle increases, only $20 \%$ ( 15 out of 76 ; see Table 4 ) of the prospective teachers responded from a mathematical perspective, while $63 \%$ (48 out of 76 ) still believed that undertaking more measurement trials would reveal a better approximate value of $\pi$, and answered the question on this basis. The students' questions referred to two aspects: whether $\pi$ is a fixed value, and whether it increases with respect to the size of the circle. However, more trials may result in fluctuating values of $\pi$; they do not help to explain its constant nature. In this respect, we can see that the KPT of prospective teachers is relatively weak. 
Table 4.Distribution of prospective teachers' perspectives on judging the constant nature of $\pi$

\begin{tabular}{ccccccc}
\hline \multirow{3}{*}{ Counts } & Mathematical & Didactical & Practical & $\begin{array}{c}\text { Irrelevant/ } \\
\text { others }\end{array}$ & Blank & Total \\
\cline { 2 - 7 } & 15 & 1 & 48 & 8 & 4 & 76 \\
& $20 \%$ & $1 \%$ & $63 \%$ & $11 \%$ & $5 \%$ & \\
\hline
\end{tabular}

\section{Choice of formal proof of the constant nature of $\pi$ in a lesson}

More than $43 \%$ of the prospective teachers chose Method A (Table 5), which involves telling students to measure the circumference and diameter of a circle and calculate their ratio. However, these prospective teachers paid most attention to accuracy rather than to the mathematical definition.

Table 5.Preference for (and explanation of) methods by prospective teachers in their lessons

\begin{tabular}{ccccccc}
\hline Choices & $\begin{array}{c}\text { Mathe- } \\
\text { matical }\end{array}$ & Didactical & Practical & Irrelevant & Blank & Total \\
\hline Method A & 5 & 22 & 4 & 2 & 0 & $33(43.4 \%)$ \\
Method B & 0 & 0 & 0 & 0 & 0 & $0(0.0 \%)$ \\
Method C & 12 & 10 & 0 & 1 & 1 & $24(31.6 \%)$ \\
Others & 1 & 3 & 1 & 5 & 9 & $19(25.0 \%)$ \\
\hline Total & 18 & 35 & 5 & 8 & 10 & 76 \\
\hline
\end{tabular}

Twenty-four prospective teachers (31.5\%) adopted the linearity method, with almost half of them believing that this method (Method C) makes it easier for students to construct the concept of a constant $\pi$. The other half adopted this method because a straight line is easier to draw correctly, which implies the concept of a constant $\pi$. We select two particular responses by way of illustration. In the first, the prospective teacher explained that the slope of a straight line connecting points of ordered pairs (circumference, diameter) leads to a proof of the constant nature of $\pi$, as the slope of a straight line is always a fixed value (Script 002, in which some parts are not explained clearly). The other prospective teacher (Script 041) correctly explained from a didactical perspective that the linear relationship of the circumference and diameter plays a key role in showing the constant nature of $\pi$, and that this is particularly useful in science subjects (See Figure 2). He/she also explained the reason errors occur, and said that errors are acceptable in an experiment like this. This demonstrates the richness of both the KPT and KRTA of this particular prospective teacher. Unfortunately, only 24 of the participants chose to employ this method, and just $12(16 \%)$ of them could apply the concept of linearity appropriately to argue for the constant nature of $\pi$. This low percentage 
indicates that our prospective teachers' knowledge of the topic is relatively weak.

Unexpectedly, 9 of the 76 prospective teachers did not respond to this question (blank responses). It is not known which of the three methods these prospective teachers prefer as an alternative, as they did not nominate one. This shows that prospective teachers seem unprepared to teach the concept of a constant, and are not ready to explain this property in their lessons.
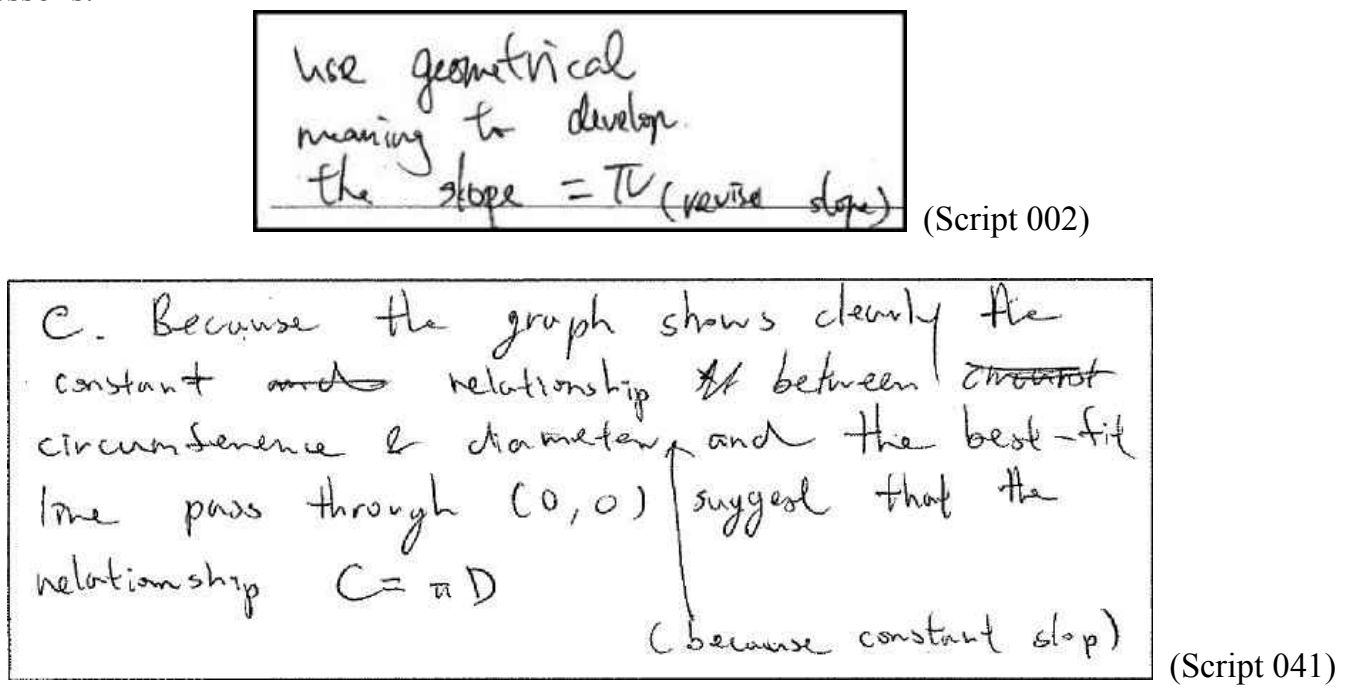

Figure2.The explanations given by two prospective teachers (Scripts 002 and 041) on using the concept of thelinearity of a straight line plotted on a coordinate system

\section{Connection between algebraic and geometric concepts}

Twenty (26.3\%; see Table 6) of the prospective teachers claimed they had no idea how to explain that $\pi$ is a constant (blank responses), while 15 (20\%) used historic events and justifications given by many mathematicians, or online information, as sources to persuade students to accept that $\pi$ is a constant. Of these 15 prospective teachers, only 6 explained that $\pi$ is a constant using the similarity of circles. Of the prospective teachers, $17+11=28(36.9 \%)$ sought to improve the accuracy of experimental measurements using computer software or more sophisticated tools (such as Taylor's series expansion, a method not taught at the lower secondary level) as an indirect means of verifying that $\pi$ is a constant. They seemed unaware that improving accuracy in measuring the magnitude of $\pi$ already assumes indirectly that $\pi$ itself is a constant. Such endeavours are simply aimed at finding a value as close as possible to the exact value of this constant. They were not aware that this does not represent proper proof of the constant nature of $\pi$. 
Table 6. Consideration of how to explain $\pi$ is a constant ( $* 6$ prospective teachers explained that $\pi$ is a constant by applying the similarity of circles)

\begin{tabular}{ccccccc}
\hline \multirow{3}{*}{ Counts } & Mathematical & Didactical & Practical & Irrelevant & Blank & Total \\
\cline { 2 - 7 } & 15 & 13 & 17 & 11 & 20 & 76 \\
& $19.7 \%$ & $17.1 \%$ & $22.4 \%$ & $14.5 \%$ & $26.3 \%$ & \\
\hline
\end{tabular}

\section{DISCUSSION ANDCONCLUSION}

The alternative method of proving the constant nature of $\pi$ lies in the fact that we have to connect the algebraic interpretation with a prominent geometric property of circles: any two circles are similar. The lengths of the corresponding sides of every pair of similar plane figures are proportional, thus implying that $\pi$ is a constant. The following figure showing a circular disc and its projected shadow on a parallel plane can be found in many text books illustrating the similarity of any two circles:

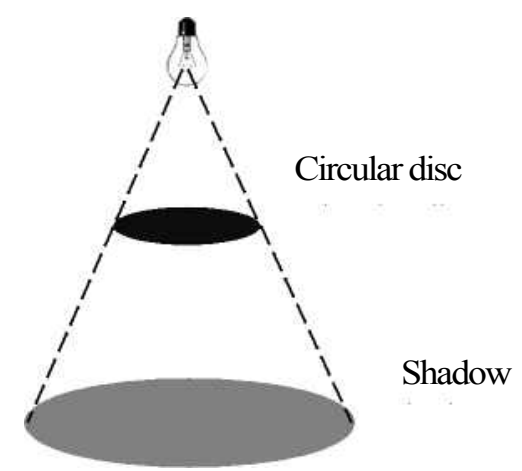

Figure3. A circular disc and its shadow under a light bulb form two parallel crosssections of a circular cone - anillustration of the similarity of two arbitrary circles

$\pi$ is defined by the ratio of the circumference of a circle to its diameter. Learners sometimes overlook the mathematical meaning of this rule for a circle. Learners and teachers who are rigorously trained in the interpretation or analysis of mathematical notions can quickly identify that this circle is arbitrary: for a given circle, without loss of generality, the ratio is considered consistent and is invariantly independent of its size. Hence, regardless of the size of the circle, the ratio $\pi$ does not change. More precisely, $\pi$ is a constant. However, this is a verbal interpretation only; does a proof of this rule exist? The answer lies in the fact that the ratio is an algebraic notion, whereas various circles sharing similar characteristics reflect a geometric 
interpretation. Prospective or in-service teachers are expected to link the algebraic result with the geometric property. It is clear that while the algebraic result gives the constant nature of $\pi$ because it is a ratio, the geometric property is linked to the ratio of the corresponding dimensions of geometric figures (circumferences and diameters in our case) by application of the property of similarity (See Figure 3). Consequently, the mathematical logic can be written as a sequential derivation of:

(i) Any two circles are similar;

(ii) The ratios of their corresponding sides (edges) are equal; and

(iii) The ratio $\pi$ of the circumference of a given circle to its diameter is a constant, regardless of the size of the circle.

A few simple deductive steps involving mathematical derivations from (i) to (iii) lead to proof of the constant nature of $\pi$. The following response demonstrates how to use similarity to prove the constant nature of $\pi$ (Script 017$)$ ):

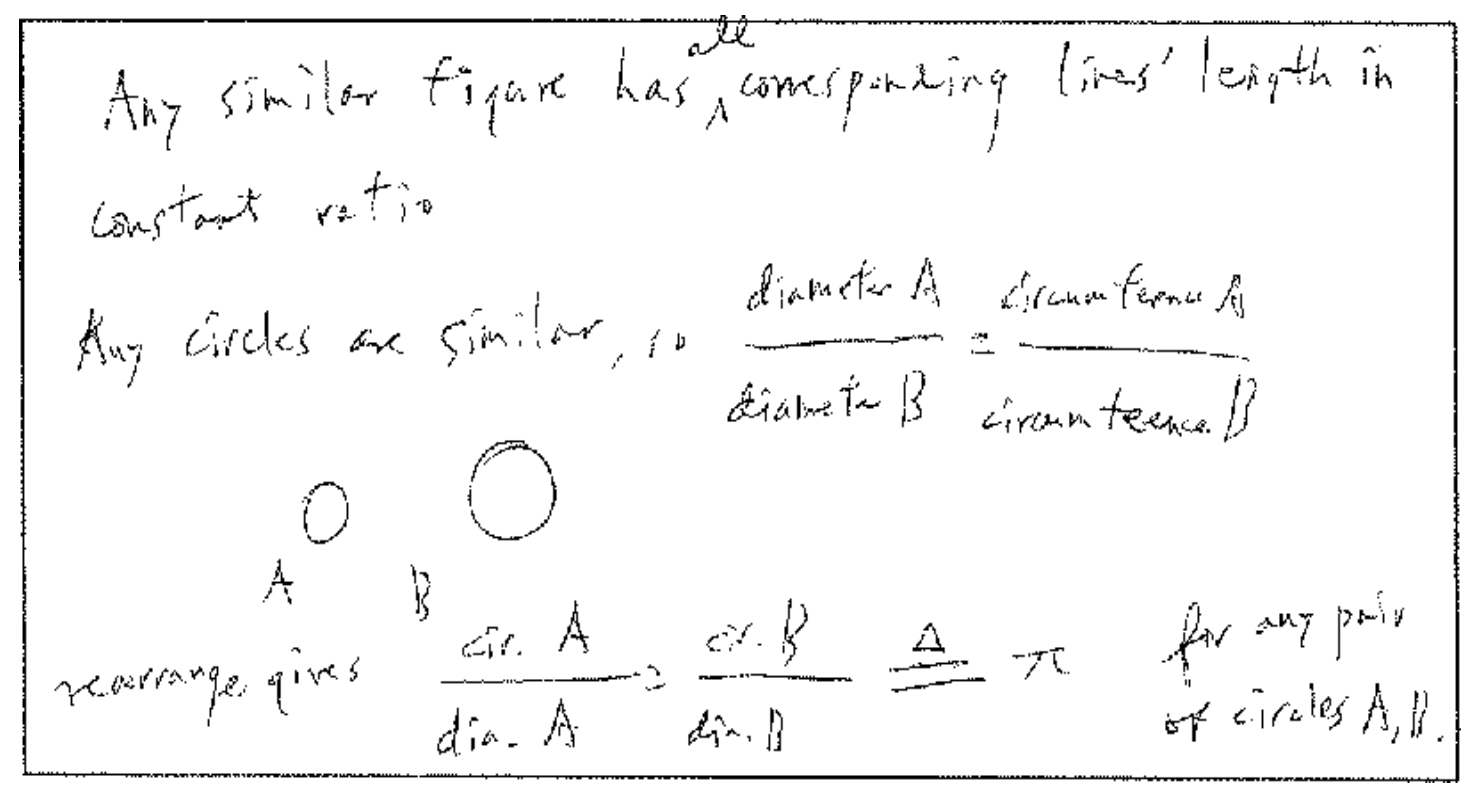

Figure 4.Valid proof of the constant property of $\pi$ by the similarity of circles.

(Script 017)

The above proof is essentially geometrical and analytic (Park, 2005). We do not need to construct many circles or use the experimental approach studied in the last section. Similarity will do the job. However, our prospective teachers seem incapable of generalising a concept (similarity of figures) for one mathematical topic (geometry) to another. Competence in 
cross-topical knowledge transfer is an essential aspect of subject content knowledge among our teachers. Our investigation illustrates why we need to enhance the subject content knowledge of pre-service teachers, particularly in their teachers college studies.

One may argue that the corresponding sizes or edges of two circles should not include the diameter, as the diameter lies inside the circle. Students may not perceive the diameter as the side or edge of a figure. However, this approach can be easily defended, as we can consider the semi-circle instead. Furthermore, each circle can be interpreted as a shape that can be decomposed into an infinite number of mutually identical isosceles triangles with the centre as their common vertex. Application of the property of similarity between any two triangles will also lead us to conclude that any two semi-circles are similar. Hence, the rule that $\pi$ is a constant can be deduced.

One may argue further that as Method A represents an initial step in Method C, prospective teachers may go no further in requiring their students to explore the linear relationship, but may instead explain the approximate value of $\pi$ under the assumption that it is a fixed value. Perhaps this is a common phenomenon that occurs in many mathematics lessons. However, the purpose of this investigation is to point out the KPT and KRTA weaknesses of our prospective teachers. Because "measuring more circles" (as in Method A) is not a proper mathematical approach to proving the constant nature of $\pi$, it can only serve to verify the approximate value of $\pi$, while the constant nature of $\pi$ is assumed as a precondition. Linearity is a very important mathematical concept students must learn to enable them to understand that one variable is linearly dependent on another. Method A represents an experimental activity which is simply a kind of pre-formal proof (see Figure 4) leading to formal proof of a proposition (Tall, 1999), whereas the concept of linearity is a catalyst acting as a pre-formal to formal bridge in the entire proof of the constant nature of $\pi$. This concept leads from an informal way (Method A in our case) to a more formal way (Method C) of reasoning in a mathematical proof (see Zandieh\& Rasmussen, 2010). It is also a kind of prerequisite knowledge enabling students and teachers to make the transition from pre-formal to formal proof (Moore, 1994). Under the secondary school curriculum, rectangular coordinate systems are taught in early secondary classes. We believe that students are capable of grasping this concept of linearity, and must learn it by plotting straight lines in a coordinate system if they are not familiar with it. Of course, the best form of preparation among competent prospective teachers is to acquire bothknowledge about the logico-linguistic structure of proof (both algebraic and geometric methods) and knowledge of situation for proving (Stylianides\& Ball, 2008) on how to prove the constant nature of $\pi$. To echo Balacheff's (2010) assertion, we cannot learn the underlying mathematical meaning of the constant property of $\pi$ without knowing how to prove it is a constant. In a similar manner, the concept of linearity can be applied in learning about the invariance of many mathematical ratios, knowledge both prospective and inservice teachers should possess. 


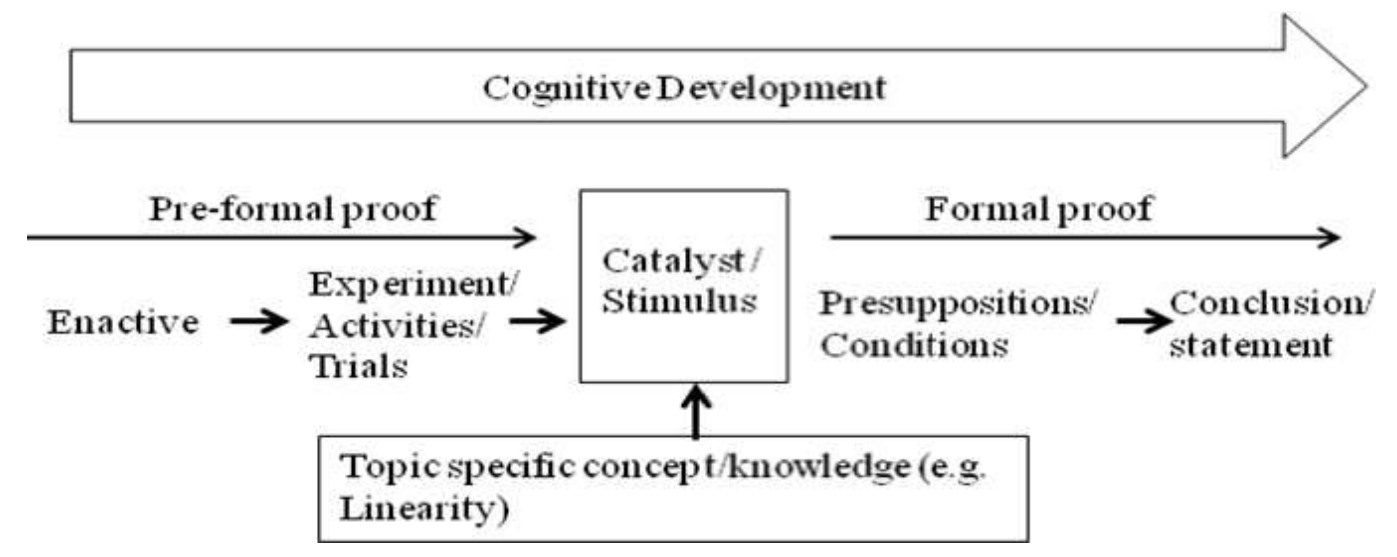

Figure5.Knowledge of linearity as a catalyst leading from pre-formal to formal proof as illustrated in themodified concept map of cognitive development of proof originally proposed by Tall (1999)

The constant slope of a straight line plotted by using points representing ordered pairs of circumferences and diameters reflects the invariance of the ratio of the circumference to the diameter, and is thus connected to the idea of the corresponding edges of similar figures having a constant ratio. Such cross-topical knowledge among teachers seems to point to the fact that subject content knowledge plays a crucial role in the smooth execution of all proving activities employed in lessons. Though our example does not solely reflect the relative importance of subject knowledge in mathematics teaching in comparison with that of pedagogical knowledge, this investigation echoes the assertion of Belfort \&Guimaraes (2002) and Li,Fan \& Zhu (2010): subject content knowledge guides pedagogy. We believe that further understanding and theoretical development is required before we can apply this concept to mathematics teacher education.

\section{REFERENCES}

Balacheff, N. (1991). Treatment of refutations: Aspects of the complexity of a constructivist approach to mathematics learning. In: E. von Glasersfeld(Ed.),Radical constructivism in mathematics education(pp. 89-110). Dordrecht, Netherlands: Kluwer. ME 1991h.02017

(2010). Bridging knowing and proving in mathematics: A didactical perspective. In: G. Hanna, H.N. Janke\& H. Pulte (Eds.),Explanation and proof in mathematics: Philosophical and educational perspectives. Based on the conference, Essen, Germany; November 2006 (pp. 115-135). Berlin:Springer. ME 2010e.00330 
Ball, D. (2005). Effects of Teachers Mathematical Knowledge for Teaching on Student Achievement.American Educational Research Journal.42(2), 371-406. ME 2008e.00467

Ball, D.;Lubienski, S. T.\&Mewborn, D. (2001). Research on teaching mathematics: The unsolved problem of teachers' mathematical knowledge. In: V. Richardson (Ed.), Handbook of research on teaching (pp. 433-456). Washington, DC: American Educational Research Association. ME 2011d.00304

Belfort, E. \&Guimaraes, L. C. (2002). The influence of subject matter on teachers' practices: Two case studies. In: A. D. Cockburn \& E. Nardi (Eds.), Proceedings of the 26th Conference of the International Group for the Psychology of Mathematics Education (Vol. 1, pp. 73-80). Norwich, UK: University of East Anglia.

Blum, W. \& Kirsch, A. (1991).Preformal proving: Examples and reflections. Educ. Stud.Math.22(2), 183-203. ME 1992a.03688

Blomhøj, M., \& Valero, P. (2007).The important and difficult task of improving mathematics teacher education [Editorial].Nordic Studies in Mathematics Education NOMAD, 12(2), 1-4.

Curriculum Development Committee, Hong Kong (CDC) (1999). Syllabus for secondary schools: mathematics (secondary 1-5). Hong Kong: Government Printer.

Curriculum Development Council, Hong Kong \& Hong Kong Examinations and Assessment Authority (CDC \& HKEAA) (2007).Mathematics education key learning area: mathematics curriculum and assessment guide (Secondary 4-6), Hong Kong: Government Printer.

Dreyfus, T. (1999). Why Johnny Can't Prove. Educ. Stud. Math.38(1-3), pp. 85-109. ME 2000d. 02330

Griffiths, P.A. (2000). Mathematics at the Turn of the Millennium.Am. Math. Mon. 107(1),1-14.

Gruenwald, N. \&Klymchuk, S. (2003). Using Counter-Examples in Teaching Calculus: Students’'Attitudes.N. Z. Math. Mag.40(2), 22-41. ME 2003f.04832

Hill, H.C.; Ball, D.L. \& Schilling, S.G. (2008). Unpacking Pedagogical Content Knowledge: Conceptualizing and Measuring Teachers' Topic-Specific Knowledge of Students. J. Res. Math. Educ.39(4), 372-400. ME 2009d.00074

Leung, K. C. I. (2013). Prospective Teachers' Understanding of the Constant $\pi$ andtheir Knowledge of How to Prove its Constant Nature through the Concept of Linearity. In: Y. Choe, O. N. Kwon\&B. E. Suh(Eds.), Proceedings of the 2013JointInternational Conference onMathematics Education held at SeoulNational University, Seoul151-742, Korea; November 1-2, 2013 (pp. 575-604). Seoul, Korea: Korean Society of Mathematical Education.

Li, J.; Fan, X. \& Zhu, Y. (2010).A framework on mathematical knowledge for teaching.In: Y. Shimizu, Y. Sekiguchi, \& K. Hino (Eds.), Proceedings of the 5th East Asia Regional Conference on Mathematics Education (EARCOME 5)(Vol. 2, pp. 1-8). Tokyo, Japan: Japan Society of Mathematics Education. 
Li, Y. \& Huang, R. (2008). Chinese elementary mathematics teachers' knowledge in mathematics and pedagogy for teaching: the case of fraction division. ZDM, Int. J. Math. Educ. 40(5), 845-859. ME 2009f.00128

Li, Y. \&Kulm, G. (2008). Knowledge and confidence of pre-service mathematics teachers: the case of fraction division. ZDM, Int. J. Math. Educ. 40(5), 833-843. ME 2009f.00116

Meel, D. E. (1999). Prospective teachers' understandings: Function and composite function. Issues Undergrad.Math. Prep. Sch. Teach. J.1(1), 1-12. ME 2000a.00514

Moore, R.C. (1994). Making the Transition to Formal Proof.Educ. Stud. Math.27(3), 249-226. ME 1999d.02259

Park, K. (2005). Mathematics Teacher Education in East Asian Countries - From the Perspective of PedagogicalContent Knowledge.Paper presented at the 3rd East Asia Regional Conference on Mathematics Education (EARCOME 3),August 7-12, 2005; Shanghai, China.

Schmidt, W.;Tatto, M.T.;Bankov, K.;Blömeke, S.;Cedillo, T.\& Cogan, L. (2007).The preparation gap: teacher education for middle school mathematics in six countries (MT21 report). East Lansing, MI: Michigan State University.

Sanchez, V. \&Llineares, S. (2003). Four Student Teachers’ Pedagogical Reasoning on Function.J. Math. Teach. Educ.6(1), 5-25. ME 2003c.02498

Schwarz, B.; Leung, I. K. C.;Buchholtz, N.; Kaiser, G.;Stillman, G.; Brown, J. \& Vale, C. (2008). Future teachers' professional knowledge on argumentation and proof: a case study from universities in threecountries. ZDM, Int. J. Math. Educ. 40(5), 791-811. ME 2009f.00114

Shulman, L. S. (1986). Those who understand: Knowledge growth in teaching. Educational Researcher57(1), 1-22.

Styliandes, G. J.;Styliandes, A. J. \&Philippou, G. N. (2007).Preservice Teachers' Knowledge of Proof by Mathematical Induction.J. Math. Teach. Educ.10(3), 145-166. ME 2010b.00342

Stylianides, A. J. \& Ball, D. L. (2008). Understanding and describing mathematical knowledge for teaching: knowledge about proof for engaging students in the activity of proving. J. Math. Teach. Educ.11(4), 307-332. ME 2009c.00067

Tall, D. (1999). The Cognitive Development of Proof: Is Mathematical Proof For All or For Some? In: Z. Usiskin (Ed.), Developments in School Mathematics Education around the World(Volume 4, pp. 117-136). Reston, VA: NCTM. ME 2000e.03103

Weber, K. (2001). Student difficulty in constructing proof: The need for strategic knowledge. Educ. Stud. Math.48(1), 101-119. ME 2002e.04039

Wong, N. Y.; Han, J. W. \& Lee, P. Y. (2004). The mathematics curriculum: towards globalisation or Westernisation? In: L. Fan, N. Y. Wong, J. Cai\& S. Li (Eds.), How Chinese learn mathematics: perspectives from insiders (pp. 27-70). Singapore: World Scientific. ME 2006c.01612 
Wu, H. (2011). The Mis-Education of Mathematics Teachers.Notices of the American Mathematical Society58(3), 372-384.

Zandieh, M. \& Rasmussen, C. (2010).Defining as a Mathematical Activity: A Framework for Characterizing Progress from Informal to More Formal Ways of Reasoning.J. Math. Behav.29(2), 57-75. ME 2011f.00394 


\section{APPENDIX I}

The item instrument:

As a teacher, you construct a circle on a chalkboard in front of your class and define the ratio by dividing the circumference of the circle by the length of its diameter. You then tell your students that this ratio is the number $\pi$. Three students conduct separate experiments to find the value of $\pi$ :

(i) Student A measures the respective circumferences and diameters of five circles and calculates the average of 3.13, and states that the ratio of the circumference to the diameter is approximately 3.13 . He also claims that $\pi$ must be a fixed value approximately equal to 3.13 .

\begin{tabular}{|c|c|c|c|}
\hline Circle & Circumference & Diameter & C/D \\
\hline 1 & 12.5 & 4.1 & 3.05 \\
\hline 2 & 17.3 & 5.6 & 3.09 \\
\hline 3 & 11.8 & 3.8 & 3.11 \\
\hline 4 & 19.2 & 6.1 & 3.15 \\
\hline 5 & 21.7 & 6.7 & 3.24 \\
\hline \multicolumn{3}{|c|}{ Average } & 3.13 \\
\hline
\end{tabular}

(ii) Student B proceeds with a similar approach to that of student A. However, he finds that the ratio of the diameter to the circumference is 0.317 (an average value measured from three circles). Taking the reciprocal of 0.317 gives 3.155 . This is $\pi$.

\begin{tabular}{|c|c|c|c|}
\hline Circle & Diameter & Circumference & D/C \\
\hline 1 & 13.4 & 42.7 & 0.3138 \\
\hline 2 & 10.7 & 33.0 & 0.3242 \\
\hline 3 & 9.6 & 30.6 & 0.3137 \\
\hline \multicolumn{3}{|c|}{ Average } & 0.317 \\
\hline
\end{tabular}

(iii) Student C looks for ordered pairs (circumference, diameter) and plots the points represented by the ordered pairs on a graph.

\begin{tabular}{|c|c|c|c|}
\hline Circle & Circumference & Diameter & $(\mathrm{D}, \mathrm{C})$ \\
\hline 1 & 9.5 & 3.0 & $(3.0,9.5)$ \\
\hline 2 & 16.4 & 5.1 & $(5.1,16.4)$ \\
\hline 3 & 24.5 & 7.9 & $(7.9,24.5)$ \\
\hline 4 & 31.4 & 10.5 & $(10.5,31.4)$ \\
\hline 5 & 41.3 & 12.8 & $(12.8,41.8)$ \\
\hline 6 & 43.8 & 14.6 & $(14.6,43.8)$ \\
\hline
\end{tabular}




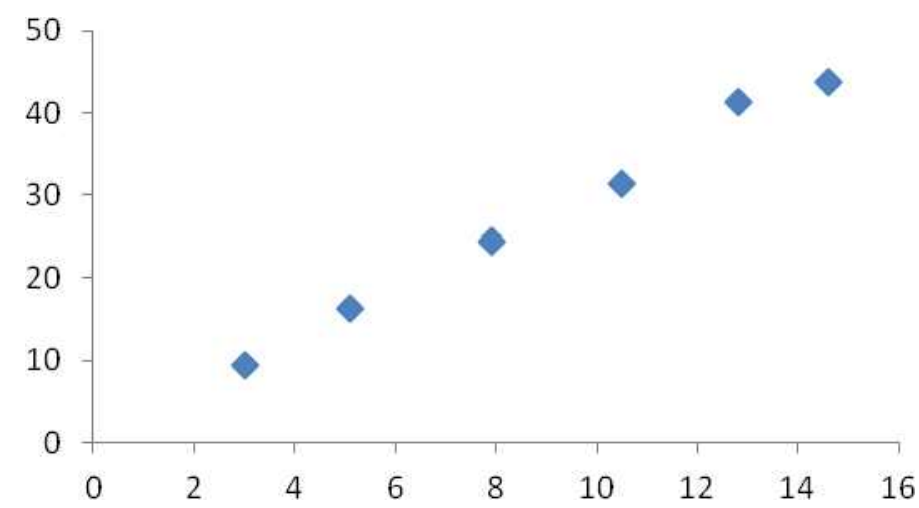

Student $C$ claims that there is some relationship between $C$ and $D$, as they increase simultaneously. Therefore, as a ratio of $\mathrm{C}$ to $\mathrm{D}, \pi$ must be a fixed number approximately equal to 3.1 .

Q1: How would you explain why the students find different values of $\pi$ fromtheir measurements?

Q2: Because there are discrepancies in estimating the value of $\pi$, can you suggest any methods to improve the estimated value?

Q3: As a teacher, please comment the advantagesand disadvantages of delivering the concept (definition) and property (a constant) of $\pi$ through the respective methods employed by the three students.

Q4: Student B claims that the "diameter to circumference" ratio is the reciprocal of $\pi$ and is also a constant. He questions why we do not use this number instead. How would you explain why?

Q5: Student B asks why the values are not calculated precisely, and says: "I am not convinced that $\pi$ is a constant. $\pi$ may be $3.15,3.16$ or even 3.2 for a larger circle because the circles I have drawn are larger than those of student $\mathrm{A}$; it is not $3.1416, \ldots$, it is not a constant". As a teacher, how would you respond?

Q6: Imagine you are going to teach classes of early secondary students who have some basic knowledge of what has been discussed by the three students above in relation to the property of $\pi$. Explain which method you would use in your lesson and why.

Q7: How would you explain that $\pi$ is a constant other than by using the three trial methods employed by the students above? 


\section{APPENDIX II}

Coding rubrics for the item questions:

Q1. How do you explain why the students find different values of $\pi$ from their measurements?

\begin{tabular}{|c|c|c|c|}
\hline \multirow{2}{*}{ Category } & Definition & Encoding rules & Examples \\
\hline A & Mathematical & $\begin{array}{c}\text { Discrepancy due to students' } \\
\text { weakness of knowledge }\end{array}$ & $\begin{array}{c}\text { Do not know the meaning of } \\
\text { ratio, rounding off skill }\end{array}$ \\
\hline B & $\begin{array}{c}\text { Didactical - consider- } \\
\text { ing students' basic } \\
\text { skills of doing expe- } \\
\text { riments }\end{array}$ & $\begin{array}{c}\text { Students do not understand } \\
\text { teachers' instruction proper- } \\
\text { ly; disciplinary reasons; } \\
\text { teacher's classroom man- } \\
\text { agement }\end{array}$ & $\begin{array}{c}\text { Environmental / experimental } \\
\text { set up is not proper; too many } \\
\text { students in a group, students } \\
\text { cannot compromise a suitable } \\
\text { approach }\end{array}$ \\
\hline C & $\begin{array}{c}\text { Practical / 1stprinciple } \\
\text { due to experiment } \\
\text { set up and human } \\
\text { errors }\end{array}$ & $\begin{array}{c}\text { Deduce the constant nature } \\
\text { of } \pi \text { by simply trial a few } \\
\text { morecircles; totally experi- } \\
\text { mental approach }\end{array}$ & $\begin{array}{c}\text { Measurement errors; tool / } \\
\text { instrumental errors } \\
\text { Different methods of measure- } \\
\text { ment of diameters and circumfe- } \\
\text { rence }\end{array}$ \\
\hline D & Irrelevant / others & $\begin{array}{c}\text { Environment reasons, or } \\
\text { other reasons not related to } \\
\text { anyone of the above three } \\
\text { categories }\end{array}$ & $\begin{array}{c}\text { Students are lack of interest due } \\
\text { to other reasons such as feeling } \\
\text { tired of working }\end{array}$ \\
\hline
\end{tabular}

Q2. Since there is discrepancy in estimating the value of $\pi$, can you suggest any methods to improve it? 


\begin{tabular}{|c|c|c|c|}
\hline $\begin{array}{l}\text { Cate- } \\
\text { gory }\end{array}$ & Definition & Encoding rules & Examples \\
\hline \multirow[t]{2}{*}{$\mathrm{A}$} & $\begin{array}{l}\text { Mathematical } \\
\text { consideration }\end{array}$ & $\begin{array}{l}\text { Reasonsof mathematicalk- } \\
\text { nowledge }\end{array}$ & $\begin{array}{l}\text { understand the meaning of } \\
\text { errors, } \\
\text { review the definition of } \pi\end{array}$ \\
\hline & Practical/1stprinciple & $\begin{array}{c}\text { suggesttousemore } \\
\text { sophisticatedtoolsand } \\
\text { methods } \\
\text { get more data } \\
\text { use a larger circle }\end{array}$ & $\begin{array}{l}\text { measure more circles } \\
\text { use a better calculator / use } \\
\text { computerprogrammingto } \\
\text { calculate } \\
\text { considertousemore } \\
\text { significant figures }\end{array}$ \\
\hline $\mathrm{B}$ & $\begin{array}{l}\quad \text { Didactical- } \\
\text { considering students' } \\
\text { basic skills of doing } \\
\text { experiments }\end{array}$ & $\begin{array}{l}\text { Give incentive to students to } \\
\text { make them do it in a more } \\
\text { positive manner } \\
\text { Reduce their class work load }\end{array}$ & $\begin{array}{l}\text { Puttheexperiment as } \\
\text { acontest,give pricetothe } \\
\text { winner / winner group. } \\
\text { measure one circle by one } \\
\text { student } \\
\text { same person measure } \\
\text { circles all }\end{array}$ \\
\hline $\mathrm{C}$ & Irrelevant/others & $\begin{array}{l}\text { Other reasons not related to } \\
\text { anyone of the above three } \\
\text { categories }\end{array}$ & $\begin{array}{l}\text { Provide data directly to stu- } \\
\text { dents }\end{array}$ \\
\hline
\end{tabular}

Q3. Being a teacher, please comment the advantages and disadvantages of delivering the concept (definition) and property (a constant) of $\pi$ through the methods employed by the three students respectively. 
Advantages

\begin{tabular}{|l|l|l|l|}
\hline $\begin{array}{c}\text { Cate- } \\
\text { gory }\end{array}$ & \multicolumn{1}{|c|}{ Definition } & \multicolumn{1}{c|}{ Encoding rules } & \multicolumn{1}{c|}{ Examples } \\
\hline A & $\begin{array}{l}\text { Mathematical } \\
\text { consideration } \\
\text { properties }\end{array}$ & $\begin{array}{l}\text { Consider the mathematical } \\
\text { B }\end{array}$ & $\begin{array}{l}\text { Students know applying mean as } \\
\text { a number for approximation. } \\
\text { Constant property can be shown }\end{array}$ \\
\hline C & $\begin{array}{l}\text { Practical } \\
\text { consideration }\end{array}$ & $\begin{array}{l}\text { Consideral } \\
\text { Procedureoftheexperiment } \\
\text { Studentcentered } \\
\text { consideration }\end{array}$ & $\begin{array}{l}\text { Explorative, students can discov- } \\
\text { er mathematical concept them- } \\
\text { selves }\end{array}$ \\
\hline D & Others & $\begin{array}{l}\text { Teacher-centered, envi- } \\
\text { ronmentfactors; } \\
\text { classroom management }\end{array}$ & $\begin{array}{l}\text { Visible } \\
\text { Teacher can easily manelves } \\
\text { expected ans } \\
\text { of teaching and time }\end{array}$ \\
\hline
\end{tabular}

Disadvantages

\begin{tabular}{|c|c|l|l|}
\hline $\begin{array}{c}\text { Cate- } \\
\text { gory }\end{array}$ & Definition & \multicolumn{1}{|c|}{ Encoding rules } & \multicolumn{1}{c|}{ Examples } \\
\hline A & $\begin{array}{l}\text { Mathematical } \\
\text { consideration }\end{array}$ & $\begin{array}{l}\text { Consider the mathematical } \\
\text { properties }\end{array}$ & $\begin{array}{l}\text { Student need to have the con- } \\
\text { ceptof slope of the best fitted line } \\
\text { Line may not go through } \\
\text { the origin }\end{array}$ \\
\hline B & $\begin{array}{l}\text { Didactical } \\
\text { consideration }\end{array}$ & $\begin{array}{l}\text { Curriculum related; } \\
\text { Studentcentered } \\
\text { consideration }\end{array}$ & $\begin{array}{l}\text { Students just stay at the level of } \\
\text { manipulation but not geometrical- } \\
\text { ly understanding }\end{array}$ \\
\hline C & $\begin{array}{c}\text { Practical } \\
\text { consideration }\end{array}$ & $\begin{array}{l}\text { Considerthe method/ } \\
\text { Procedureofthe } \\
\text { experiment }\end{array}$ & $\begin{array}{l}\text { Difficult to measure; take } \\
\text { long time to measure } \\
\text { Discrepancy in results }\end{array}$ \\
\hline D & Other & $\begin{array}{l}\text { Teacher-centered, envi- } \\
\text { ronmentfactors; } \\
\text { classroom management }\end{array}$ & $\begin{array}{l}\text { Answer is invisible; seems no } \\
\text { fixed numerical value for } \pi\end{array}$ \\
\hline
\end{tabular}

Q4. Student B claims that the ratio: "diameter to circumference" is the reciprocal of $\pi$ and is also a constant. He questions that why we do not use this number instead. How will you explain? 


\begin{tabular}{|c|c|c|c|}
\hline $\begin{array}{l}\text { Cate- } \\
\text { gory }\end{array}$ & Definition & Encoding rules & Examples \\
\hline $\mathrm{A}$ & $\begin{array}{l}\text { Mathematical } \\
\text { consideration }\end{array}$ & $\begin{array}{l}\text { Considerthemathematical } \\
\text { properties }\end{array}$ & $\begin{array}{l}\pi \text { is not only related to circumfe- } \\
\text { rence but also area of the circle }\end{array}$ \\
\hline B & $\begin{array}{l}\text { Didactical } \\
\text { consideration }\end{array}$ & $\begin{array}{l}\text { The circumference } \\
\text { area formula are in linear } \\
\text { form, which can be easily } \\
\text { memorized by students }\end{array}$ & $\begin{array}{l}\text { Such a } \pi \text { can easily lead to the } \\
\text { linear expression } 2 \pi r \text {, or } \pi r^{2} \text {; if } \\
\text { we use diameter to circumfe- } \\
\text { rence for the ratio of } \pi \text { then } \\
\text { we shall haveirrationaldeno- } \\
\text { minators intheformula of circum- } \\
\text { ference and area }\end{array}$ \\
\hline $\mathrm{C}$ & $\begin{array}{l}\text { Practical } \\
\text { consideration }\end{array}$ & $\begin{array}{l}\text { Considerthemethod/ } \\
\text { Procedureofthe } \\
\text { experiment; convenient to } \\
\text { use "circumference to } \\
\text { diameter" }\end{array}$ & $\begin{array}{l}1 \text { Easy to measure } \pi \text {, but not } \\
\text { itsreciprocal. } \\
\text { - First have circumference before } \\
\text { we can find the diameter } \\
\text { - It is more convenient to use } \pi \text { that } \\
\text { is larger than } 1 \text {. }\end{array}$ \\
\hline $\mathrm{D}$ & Other & It is only a convention & $\begin{array}{l}\text { 1 Easy to measure } \pi \text {, but not } \\
\text { itsreciprocal. }\end{array}$ \\
\hline
\end{tabular}

Q5 Student B asks that the values are not exactly calculated and says: "It is not convincing that $\pi$ is a constant. $\pi$ may be $3.15,3.16$ or even 3.2 for a larger circle because my circles drawn are larger than those of student A's ; it is not 3.1416,..., it is not a constant". As a teacher, how will you response? 


\begin{tabular}{|c|l|l|l|}
\hline $\begin{array}{c}\text { Cate- } \\
\text { gory }\end{array}$ & \multicolumn{1}{|c|}{ Definition } & \multicolumn{1}{c|}{ Encoding rules } & \multicolumn{1}{c|}{ Examples } \\
\hline A & $\begin{array}{l}\text { Mathematical } \\
\text { consideration }\end{array}$ & $\begin{array}{l}\text { Manyscientif- } \\
\text { ic/mathematicsrulesandForm } \\
\text { ulacannotbeAppliedif } \pi \text { is } \\
\text { not a } \\
\text { constant }\end{array}$ & $\begin{array}{l}\text { - Diameter is also larger for } \\
\text { larger circle } \\
\text { The circumference and the } \\
\text { diameter of a circle increase } \\
\text { correspondingly, simultaneously }\end{array}$ \\
\hline B & $\begin{array}{l}\text { Didactical } \\
\text { consideration }\end{array}$ & $\begin{array}{l}\text { Use a direct method to } \\
\text { convince student B; ask } \\
\text { him/her to measure the } \\
\text { length carefully and } \\
\text { de mon strate that } \pi \\
\text { remains the same value } \\
\text { for larger circles }\end{array}$ & $\begin{array}{l}\text { Telling the students that it should be } \\
\text { a constant; The proof of the } \\
\text { constant nature of } \pi \text { will be } \\
\text { learnt in higher level }\end{array}$ \\
\hline $\mathrm{C}$ & $\begin{array}{l}\text { Practical } \\
\text { consideration }\end{array}$ & $\begin{array}{l}\text { Considerthemethod/ } \\
\text { Procedureofthe } \\
\text { experiment;useother } \\
\text { methodsto measure } \\
\text { again }\end{array}$ & $\begin{array}{l}\text { Measurementerror; orthere is } \\
\text { another better methodto verify } \\
\text { the constant nature of } \pi\end{array}$ \\
\hline $\mathrm{D}$ & Other & $\begin{array}{l}\text { Manymathematician } \\
\text { have calculate the value of } \\
\pi\end{array}$ & $\begin{array}{l}\pi \text { is a fixed number that has } \\
\text { been verified long time ago }\end{array}$ \\
\hline
\end{tabular}

Q6. Imagine you are going to teach classes of early secondary students, who have some basic knowledge of what have been discussed by the three students above, about the property of $\pi$, tell which method and why you will use it in your lesson?

\begin{tabular}{|c|l|l|}
\hline Methods & Frequency & \multicolumn{1}{c|}{ Remarks / reasons } \\
\hline Student A's & & A direct and easy method \\
\hline Student B's & & Taking the reciprocal afterward \\
\hline Student C's & & Learn the concept of linear relationship \\
\hline
\end{tabular}

Q7. How would you tell that $\pi$ is a constant besides these three trial methods employed by students above? 


\begin{tabular}{|c|c|c|c|}
\hline $\begin{array}{l}\text { Cate- } \\
\text { gory }\end{array}$ & Definition & Encoding rules & Examples \\
\hline A & $\begin{array}{l}\text { Mathematical } \\
\text { consideration }\end{array}$ & $\begin{array}{l}\text { Relationship between area } \\
\text { and diameter/ radius; } \\
\text { Using similarity of circles } \\
\text { - circles are similar } \\
\text { Approximate area of circle } \\
\text { by polygons, then calcu- } \\
\text { late the value of } \pi\end{array}$ & $\begin{array}{l}\text { 1. UseArea =and } \\
\text { count the grids. }\end{array}$ \\
\hline $\mathrm{B}$ & $\begin{array}{l}\text { Didactical } \\
\text { consideration }\end{array}$ & $\begin{array}{l}\text { Askstudentstoaccept by } \\
\text { considering students' abilities to } \\
\text { understand later the } \\
\text { other advanced methods to } \\
\text { verify the constant nature of } \pi\end{array}$ & $\begin{array}{l}\text { lithasbeen calculated } \\
\text { Manymathematicians } \\
\text { Timeagothrough } \\
\text { approximation method }\end{array}$ \\
\hline $\mathrm{C}$ & $\begin{array}{l}\text { Practical } \\
\text { consideration } \\
\text { and others }\end{array}$ & $\begin{array}{l}\text { The experiment of measure- } \\
\text { ments are just a verification; it } \\
\text { is not worth to spend time to } \\
\text { argue the constant nature }\end{array}$ & $\begin{array}{l}\text { Sincecircumferenceisa } \\
\text { curve, diameter is a straight } \\
\text { line, we have to take the } \\
\text { approximation }\end{array}$ \\
\hline $\mathrm{D}$ & Other & Use other tools & Using computer \\
\hline
\end{tabular}

